\title{
IMPLEMENTASI ZACHMAN FRAMEWORK UNTUK PEMODELAN DAN PERANCANGAN SISTEM E-COMMERCE PADA SEKTOR PERDAGANGAN IKM
}

\author{
Siti Eka Chotimah ${ }^{1)}$, Sri Handayaningsih ${ }^{2)}$ \\ 1), 2) Teknik Informatika Universitas Ahmad Dahlan Yogyakarta \\ Jl. Prof.Dr.Soepomo, Janturan, Warungboto, Yogyakarta 55164 \\ Email : sitiekachotimah@gmail.com ${ }^{1)}$, sriningsih@tif.uad.ac.id $^{21}$
}

\begin{abstract}
Trade area is an area that is in Disperindagkop DIY. In performing the task in terms of facilitating, coaching and supervision of trading activities are still experiencing difficulties in getting data such as turnover and the products produced and sold by the merchant SMEs, the number of traders SMEs. Office http://jogjaplaza.com already have a website, which is used specifically to market the products of SMEs has not reached to the industry. Based on this problem, it needs to make a model and system design appropriate e-commerce in the hope can be used as a reference when establishing the e-commerce.Tahapan used in the modeling and design of e-commerce systems Disperindagkop domestic trade field include: (1) data collection with library research techniques, interviews and observation. (2) analysis of current conditions and expected (3) Analysis of Gap and (4) development of modeling and designing systems with methods Zachman framework and models of linear sequential process. (5) The test document using analytical testing and usability testing. The research resulted in a model and e-commerce system design that can be used as a reference in the development of e-commerce system based on the results of testing with a test value for $100 \%$ testing analysis and for testing usability testing to the respondent purchaser merchant value IKM value 3.33 .1 and 3. Shows the value Service employee satisfaction or user acceptance on the model.
\end{abstract}

Keywords: SME, Model and Design, E-Commerce System, Zachman Framework

\begin{abstract}
Abstrak
Bidang perdagangan merupakan bidang yang ada di Disperindagkop DIY. Dalam melaksanakan tugas pada hal menfasilitasi, pembinaan dan pengawasan kegiatan perdagangan masih mengalami kesulitan dalam mendapatkan data seperti omzet dan produk yang dihasilkan dan dijual oleh pedagang IKM, jumlah pedagang IKM. Dinas sudah mempunyai sebuah website http://jogjaplaza.com, yang digunakan khusus untuk memasarkan produk UKM belum sampai pada ke Industri. Berdasarkan permasalah ini, maka perlu dibuat sebuah model dan perancangan sistem e-commerce yang tepat dengan harapan dapat dijadikan acuan pada saat membangun sistem e-commerce.Tahapan yang digunakan dalam pembuatan model dan perancangan sistem e-commerce Disperindagkop bidang Perdagangan dalam negeri meliputi : (1) pengumpulan data dengan teknik studi pustaka, wawancara dan observasi. (2) analisis Kondisi saat ini dan yang diharapkan (3) Analisis Gap dan (4) pembuatan pemodelan dan perancangan sistem dengan metode zachman framework dan model proses sekuensial linier. (5) Pengujian dokumen menggunakan pengujian analisis dan pengujian usability. Dari penelitian menghasilkan model dan perancangan sistem e-commerce yang dapat digunakan sebagai acuan dalam pengembangan sistem e-commerce berdasarkan hasil pengujian dengan nilai pengujian untuk pengujian analisis $100 \%$ dan untuk pengujian usability testing untuk responden pembeli nilai 3,3 pedagang IKM nilai 3,1 dan pegawai Dinas nilai 3. Menunjukkan kepuasan atau penerimaan pengguna pada model tersebut.
\end{abstract}

Kata Kunci : IKM , Model dan Perancangan, Sistem E-Commerce, Zachman Framework 


\section{PENDAHULUAN}

Perkembangan teknologi informasi dan komunikasi saat ini telah mengalami kemajuan pesat. Dengan kemajuan teknologi dan informasi, perusahan atau organisasi melakukan usaha peningkatan mutu dan daya saing yang didukung oleh teknologi informasi dan komunikasi.

Jony Wong (2010) mengatakan e-commerce adalah pembelian, penjualan dan pemasaran barang serta jasa melalui sistem elektronik. Banyak kemudahan yang didapatkan dari $e$ commerce salah satunya pedagang tidak perlu menggelar dagangannya di pasar karena dengan menggunakan e-commerce pedagang hanya mengupload dagangannya. Barang yang diupload dapat dilihat oleh calon pembeli dari berbagai daerah. Calon pembeli tidak perlu datang ketempat pedagang tersebut karena contoh barang sudah ada di web.

Zachman Framework pertama kali dipublikasikan oleh John Zachman pada tahun 1987 dalam tulisannya yang berjudul A Framework for Information System Architecture di IBM System Journal. Zachman Framework merupakan suatu skema untuk melakukan klasifikasi dalam pengorganisasian artifak enterprise. ZF terdiri dari 6 kolom dan 6 baris. ( John Zachman, 1987) Disperindagkop dan UKM merupakan salah satu pemerintahan yang mempunyai tugas melaksanakan urusan Pemerintah Daerah di bidang perindustrian, perdagangan, koperasi dan UKM serta kewenangan dekonsentrasi dan tugas bantuan yang diberikan oleh pemerintah. Bidang-bidang tersebut mempunyai tugas masing-masing sesuai Peraturan Gubernur Daerah Istimewa Yogyakarta Nomor 43 tahun 2008.

Berdasarkan Renstra Dinas Perindagkop dan UKM DIY 2012-2017 jumlah pedagang IKM di Kabupaten/Kota yang tercatat tahun 2012 sebanyak 81.523 IKM. Bertambahnya jumlah IKM tersebut menjadi kendala bagi Disperindagkop dalam pelayanan. Proses promosi dan pemasaran pada UKM di Yogyakarta sudah difasilitasi melalui website jogjaplaza.com. Tetapi pada web tersebut masih bercampuran atara jenis barang yang berbeda. Pada tampilan promosi tersebut tidak dibedakan jenis-jenis produk. Pada pedagang IKM sendiri belum disediakan web khusus untuk promosi dan penjualan.

Informasi kegiatan Dinas seperti pameran, temu usaha dan misi dagang belum diinformasikan secara online. Pedagang IKM mendapatkan informasi dengan datang ke Dinas, melalui informasi yang diberikan Disperindagkop kabupaten, asosiasi, pamflet dan diajak oleh Dinas. Data pedagang IKM diperoleh dari bidang perindustrian. Disperindagkop memiliki 4 sistem informasi. Diantara sistem informasi tersebut belum ada sistem yang menerapkan strategi khusus mendata pedagang IKM.

Pemanfaatan sistem informasi dan teknologi dapat mendukung proses bisnis yang telah ada. Namun untuk mengaplikasikannya tidaklah mudah. Oleh karena itu, pihak birokrasi pemerintah perlu membuat sistem e-commerce agar Dinas mendapatkan data-data secara up-todate dan keseluruhan yaitu meliputi jumlah pedagang IKM di Yogyakarta, daftar pedagang IKM, jenis produk yang dijual oleh para pedagang IKM. Zachman Framework membantu menggambarkan implementasi sistem dan teknologi selaras dengan model bisnis (Luftman, 2003)

\section{METODE PENELITIAN}

Pada Metode penelitian, tahapan yang dilakukan meliputi :

2. 1. Pengumpulan Data

Proses pengumpulan data menggunakan teknik kajian pustaka dan literatur, observasi dan wawancara.

2. 2. Analisis Data

Hasil Pengumpulan data, kemudian dilakukan analisis untuk mengetahui :

1) Kondisi saat ini

2) Kondisi yang diharapkan

3) SWOT

\section{3. Pemodel Proses Bisnis Baru}

Memodelkan proses bisnis baru untuk pelayanan Dinas di bidang perdagangan ke IKM. Pemodelan proses bisnis menggunakan konsep BPMN (Business Process Management Notation). 
2. 4. Kebutuhan Sistem

Memaparkan kebutuhan sistem e-commerce berdasarkan model proses bisnis yang baru.

2. 5. Pemodelan Data

Data akan dimodelkan dengan ERD keterkaitan antar data berdasarkan proses bisnis bidang perdagangan.

2. 6. Arsitektur Aplikasi

Arsitektur Aplikasi menggambarkan kebutuhan modul dalam aplikasi e-commerce yang akan digunakan untuk mendukung proses bisnis di Bidang Perdagangan.

2. 7. Rancangan User Interface

Merancang interface untuk sistem e-commerce.

2. 8. Pengujian

1. Pengujian Analisis merupakan pengujian terhadap analisis yang telah dibuat apakah dapat direkomendasikan untuk Disperindagkop bidang perdagangan dalam negeri.

2. Pengujian Usability

a) Pengujian Penerimaan (usability testing) adalah pengujian dengan memberikan sejumlah tugas yang sudah dipersiapkan sebelumnya. Tugas diberikan kepada 2 pegawai, 15 pedagang IKM dan 30 pembeli. Tugas ini digunakan sebagai 'sarana interaksi dalam pengukuran usability.

b) Analisa usability testing adalah rekap terhadap hasil kuisioner yang telah disebar.

2. 9. Rekomendasi

Memberikan rekomendasi terkait dengan hasil pembuatan perancangan dan pemodelan sistem e-commerce. Pembuatan rekomendasi didasarkan pada hasil pengujian rancangan.

\section{HASIL DAN PEMBAHASAN}

Dalam pengembangan model ecommerce, menggunakan kerangka kerja zachman agar model yang dihasilkan selaras dengan bisnis yang berjalan di Dinas (Juan dkk, 2013), yaitu berdasarkan proses bisnis yang berjalan dan tujuan yang ingin dicapai.

\section{1. Analisis Kondisi Saat ini}

a. Proses bisnis yang berjalan di bidang perdagangan dalam negeri seperti yang tertera pada peraturan Gubernur No 43 tahun 2008, digambarkan seperti pada gambar 1, terkait tentang pendataan pedagang dan produk hasil IKM dan proses kegiatan pameran.

Proses bisnis secara umum antara bidang perdagangan dalam negeri, Pedagang IKM dan pembeli adalah bidang perdagangan memasarkan produk hasil pedagang IKM, pembeli membeli produk pedagang IKM. Pedagang IKM juga melakukan penjualan dengan pemeran, temu usaha dan misi dagang. 


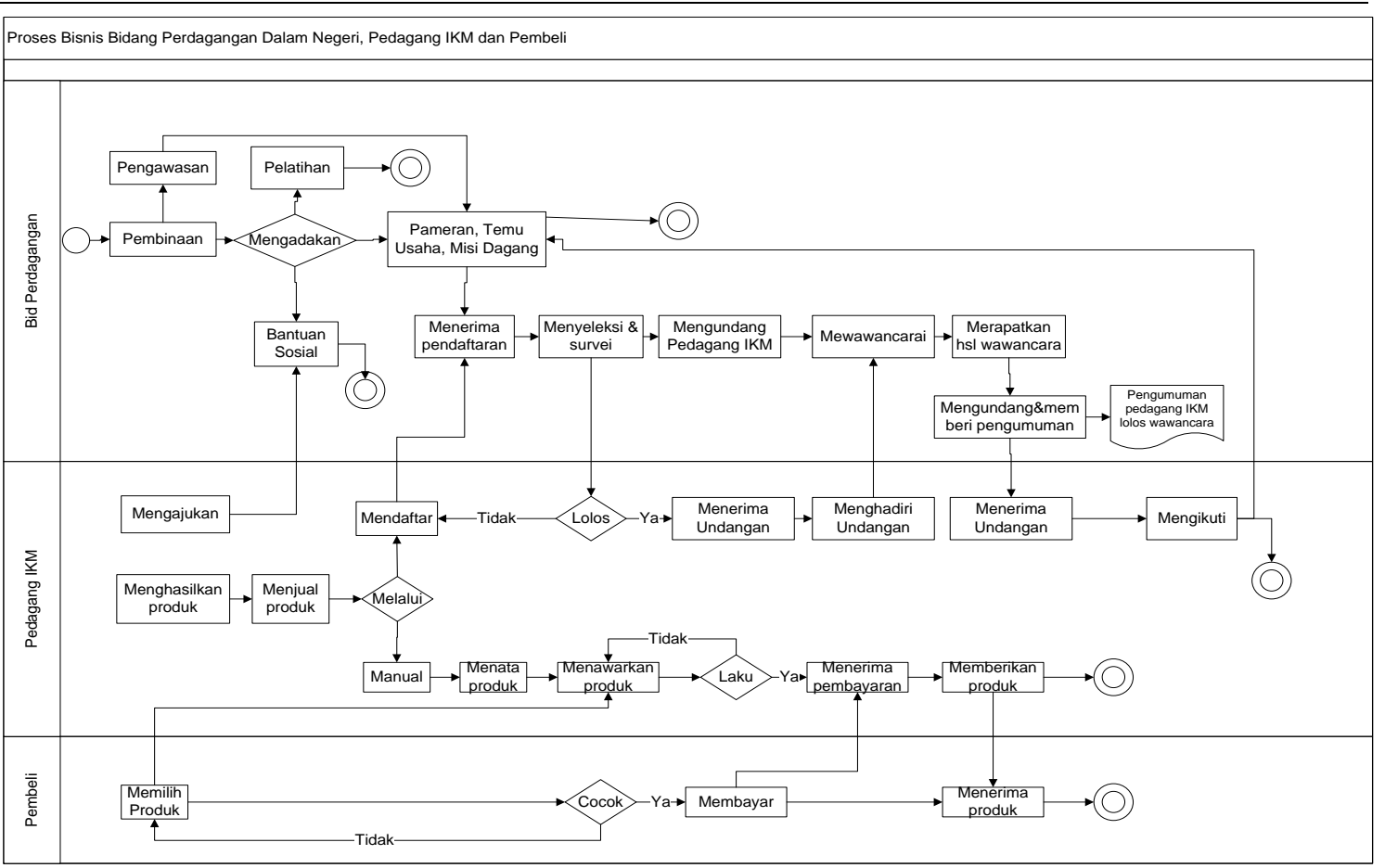

Gambar 1. Proses bisnis bidang perdagangan dalam negeri, pedagang IKM dan pembeli

b. Sistem Informasi/Aplikasi yang digunakan

Sistem informasi yang digunakan antara lain :

1. Website profil Disperindagkop untuk menampilkan profil Dinas secara keseluruhan.

2. Website jogja plaza, untuk mengelola hasil produk dari UKM saja, tidak mengikutkan produk hasil IKM dan belum ada transaksi penjualan di web tersebut.

3. Aplikasi SILDASI digunakan untuk mengelola sektor IKM dari sisi perijininan

4. Website balai bisnis untuk mengelola informasi tentang balai pelayanan bisnis yang ada di Yogyakarta berupa penginputan naskah, dan mengurusi website jika bermasalah.

\subsection{Kondisi yang diharapkan}

Kondisi yang diharapkan oleh Dinas Perindustrian, Perdagangan, Koperasi dan Usaha Kecil Menengah bidang perdagangan berdasarkan rentra Disperindagkop adalah pedagang IKM dapat lebih memperluas jangkauan pemasarannya dan dapat membuat bermacam-macam produk dari bahan mentah yang selama ini diolah. Pada zachman diterangkan pada sel baris 1 kolom 1.

\subsection{Analisis SWOT}

Berdasarkan kondisi saat ini dan yang diharapkan Disperindagkop dalam mengelola IKM, maka analisis SWOT yang dihasilkan adalah:

1. Kekuatan

- Memiliki 4 sistem informasi berbasis web dan desktop yang sudah membantu dalam menjalankan proses bisnis.

- Sudah adanya bidang yang bertanggung jawab pada bagian perdagangan.

2. Kelemahan

- Dinas kesulitan menghubungi IKM dan mengajak mengikuti kegiatan

- Pegawai yang mengurusi bidang perdagangan belum mencukupi. 
3. Peluang

- Jumlah IKM dari tahun ke tahun meningkat.

- Ada beberapa instansi milik pemerintah yang membantu perkembangan IKM

4. Ancaman

- Keberadaan pasar tradisional semakin menurun dengan adanya pasar modern.

- Adanya pasar bebas ASEAN 2015 produk industri luar negeri masuk ke Indonesia.

\subsection{Model Perubahan Proses Bisnis dengan Bantuan Sistem}

Model perubahan proses bisnis dengan memasukkan sistem informasi, sesuai pada zachman kolom 2 baris 1 . Sistem akan membantu proses bisnis di Disperindagkop antara lain :

1. Pendaftaran akun pedagang IKM

Bertujuan untuk mengetahui data pedagang IKM secara lengkap.

2. Pendaftaran pembeli

Bertujuan untuk mendata pembeli yang bertransaksi dengan IKM.

3. Login

Sebagai alat untuk pengamanan sistem agar pengakses sistem sesuai dengan pengguna yang berhak.

4. Promosi

Halaman dalam web yang berfungsi untuk mempromosikan produk IKM ke konsumen/pembeli.

5. Penjualan

Proses transaksi antara pedagang IKM dengan Konsumen. Bagi Disperindagkop memudahkan untuk mengetahui omset secara kasar tiap IKM.

6. Pendaftaran mengikuti pameran

Memudahkan IKM dalam mengikuti pameran dan memudahkan bagi Dinas untuk mengelola setiap even pameran dan membantu pedagang IKM untuk menjual hasil produksinya.

7. Pendaftaran mengikuti misi dagang

Membantu pedagang IKM dalam mendaftar misi dagang dan kemudahan dalam pengelolaan bagi Dinas.

8. Pendaftaran mengikuti temu usaha

Membantu pedagang IKM dalam mendaftar temu usaha dan kemudahan dalam pengelolaan bagi Dinas.

9. Pembinaan pelatihan

Proses untuk melakukan pelatihan bagi IKM berdasarkan data yang dimiliki Dinas berdasarkan data transaksi yang sudah terekap dalam sistem.

10. Pembinaan (Pameran, Misi Dagang dan Temu Usaha)

Proses untuk melakukan pembinanaan bagi kegiatan pameran, misi dagang dan temu usaha.

11. Pembinaan (bantuan sosial)

Proses melakukan pembinaan kepada IKM yang tidak mampu meneruskan usaha dengan cara memberikan modal.

12. Pegawasan Data Pedagang IKM dan Pengawasan penjualan Pameran, Misi Dagang dan Temu Usaha

Mengawasi pertumbuhan pedagang IKM berdasarkan data transaksi perdagangannya dalam sistem.

\subsection{Kebutuhan Sistem}

Kebutuhan sistem e-commerce yang akan dibangun sesuai dengan zachman baris 3 kolom 2 , meliputi 3 bagian yaitu:

1. Kebutuhan pembeli, Meliputi :

- Menu buat akun pembeli 
- Menu detail agenda Dinas

- Menu detail pengumuman

- Seleksi pameran

- Menu cara pembelian

- Tampilan login,tampilan lupa password,tampilan berhasil login

- Tampilan proses beli

- Tampilan konfirmasi pembelian

- Menu bantuan

2. Menu akun pembeli

- Menu kategori poduk.

3. Kebutuhan pedagang IKM:

- Menu login pedagang IKM

- Menu daftar pedagang IKM

- Menu lupa password pedagang IKM

- Menu promosi

- Menu penjualan

- Menu pengajuan proposal

- Menu informasi

- Tampilan daftar kegiatan Dinas

- Menu informasi pembelian

- Menu balasan Dinas pengajuan proposal

- Menu undangan Dinas

4. Kebutuhan pegawai Dinas

- Menu login pegawai

- Menu utama pegawai bidang perdagangan

- Menu tampilan daftar calon pedagang IKM mengikuti kegiatan Dinas

- Menu pembinaan pelatihan

- Menu pembinaan pameran

- Input ketentuan daftar kegiatan Dinas

- Input tahap pendaftaran kegiatan Dinas

- Menu pembinaan temu usaha

- Menu pembinaan misi dagang

- Menu pembinaan bantuan sosial

- Menu balasan pengajuan proposal

- Menu pengawasan data pedagang IKM

- Menu pengawasan penjualan(menu pengawasan penjualan tahunan

- Menu pengawasan penjualan bulanan)

- Menu pengawasan pameran

- Menu pengawasan temu usaha

- Menu pengawasan misi dagang

- Inputan menu tentang

- Inputan menu bantuan

- Menu ubah password.

\subsection{Arsitektur Data}

Arsitektur Data digambarkan dengan ERD (Entity Relationship Diagram) sesuai dengan zachman pada baris 3 kolom 1 , seperti pada gambar 2 . 


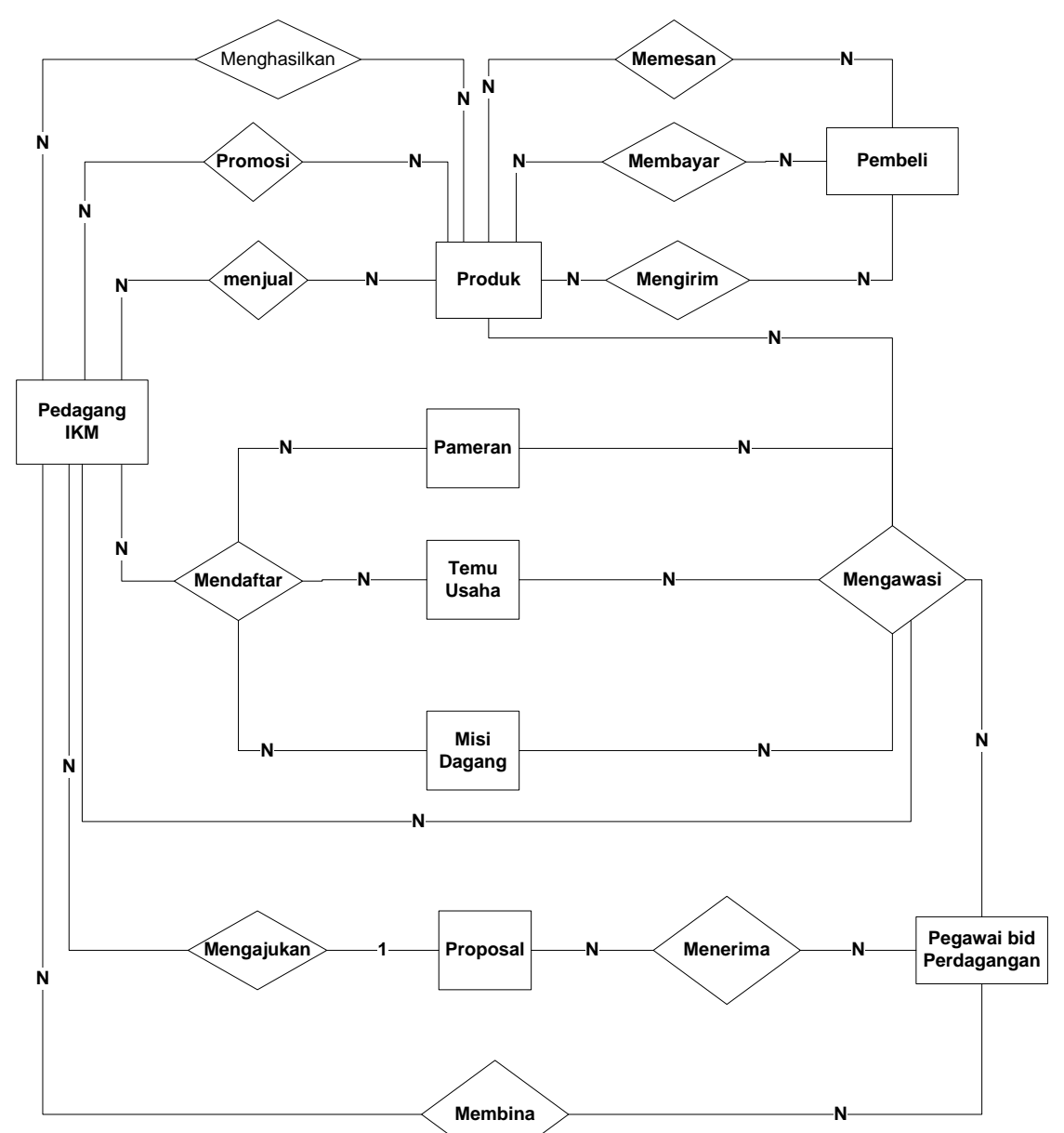

Gambar 2. Entity Relationship Diagram

\subsection{Arsitektur Aplikasi}

Arsitektur Aplikasi yang dibutuhkan oleh Bidang Perdagangan untuk mendukung proses bisnis, seperti pada zachman baris 3 kolom ke 2, digambarkan pada gambar 3 . Kebutuhan modulmodul dalam sistem e-commerce yang disesuaikan dengan pengguna yang berhak dan mempunyai hak akses. 


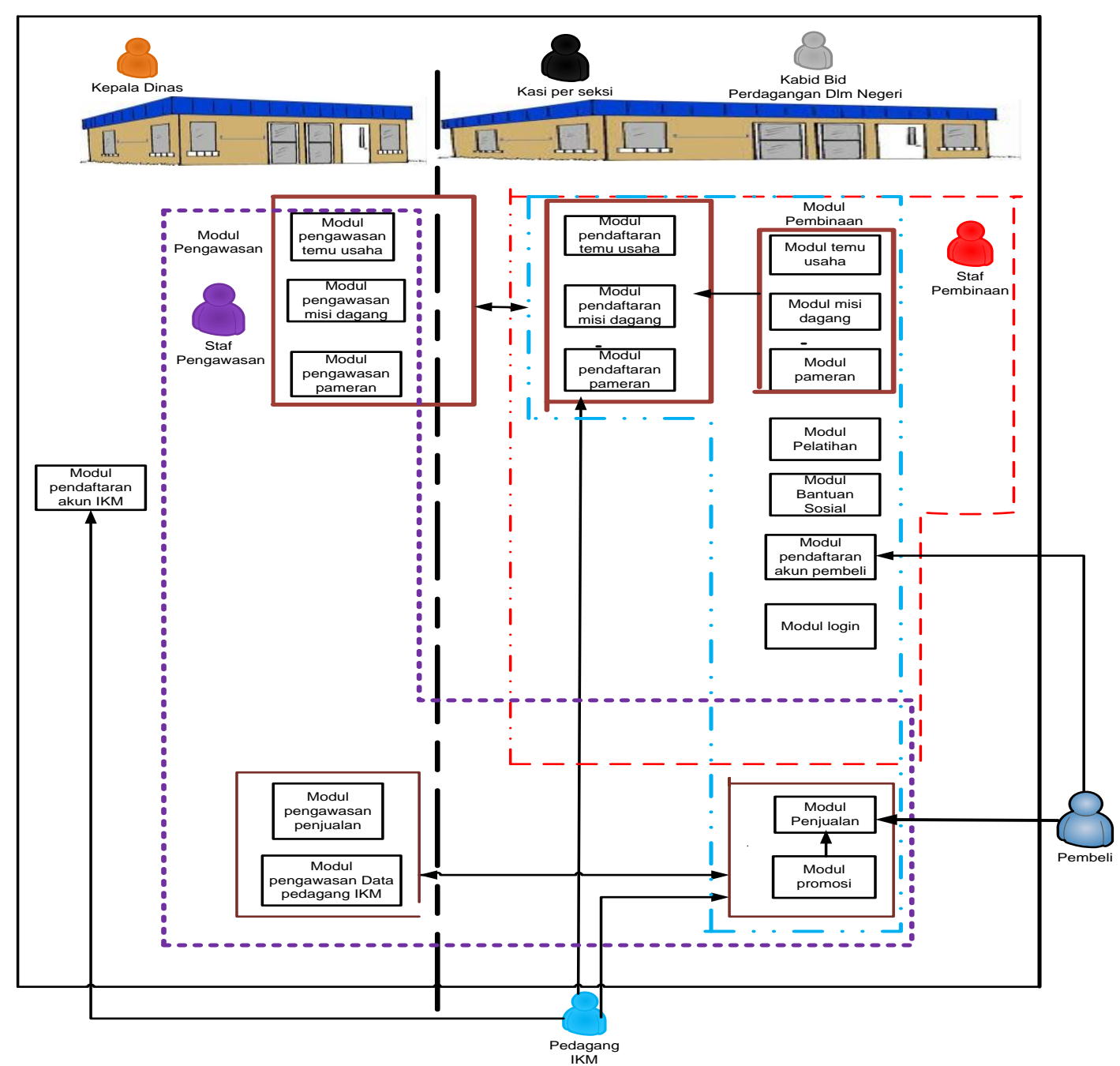

Gambar 3. Kebutuhan Modul sistem e-commerce

\subsection{Rancangan User Interface}

Rancangan user interface untuk sistem ecommerce seperti pada gambar 4. Semua kebutuhan sistem yang sudah didefinisikan disesuai dengan rancangan sistem yang sejalan dengan proses bisnis dan tujuan Dinas dan kegiatan yang berjalan pada pedagang IKM. Selain itu disesuaikan kebiasaan masa kini model e commerce saat ini yang berkembang (Fasyuri, 2012).

\subsection{Pengujian}

a. Pengujian analisis

Pengujian analisis dilakukan dengan memberikan dokumen beserta penjelasan terlebih dahulu kepada responden yaitu pegawai Dinas. Pengujian ini dilakukan dengan cara menjelaskan mengenai proses bisnis baru yang diusulkan, entitas relationship diagram, arsitektur informasi, arsitektur data, data flow diagram, arsitektur aplikasi, rancangan sistem, jaringan logistik, struktur organisasi, dan rancangan antarmuka. Dari hasil kuesioner yang diberikan bahwa analisis yang diusulkan dapat direkomendasikan untuk Dinas Perindagkop dan UKM bidang perdagangan dalam negeri dengan presentasi $100 \%$. 


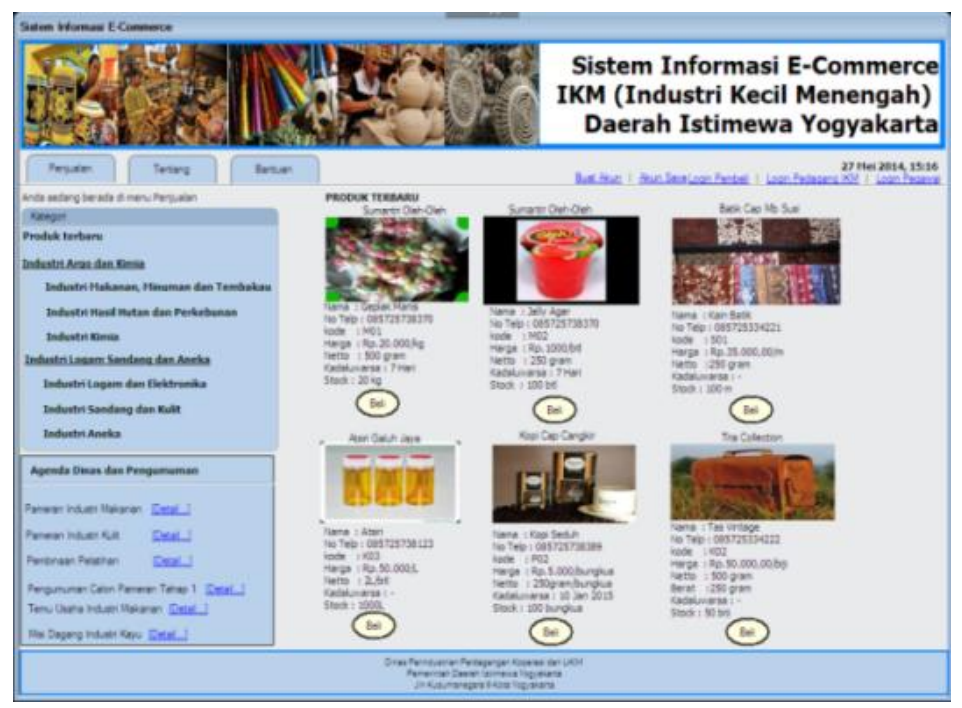

Gambar 4: Tampilan awal sistem e-commerce

b. Pengujian usability

Uji kelayakan ini dilakukan kepada pembeli, pedagang IKM, dan pegawai Dinas. Pengujian dilakukan dengan memberikan Task-Task Usability Testing dan kuesioner yang sudah dipersiapkan. Dengan hasil nilai untuk responden pembeli 3,3 pedagang IKM 3,1 dan pegawai Dinas 3. Dari pengujian yg didapat disimpulkan bahwa pengujian usability dapat diterima oleh masing-masing pengguna.

\section{10. Rekomendasi}

Rekomendasi usulan untuk Disperindagkop bidang perdagangan dalam negeri adalah sebagai berikut:

1. Pembuatan pemodelan dan perancangan sistem e-commerce ini dibangun ketika Dinas telah siap dalam hal biaya, SDM, dan siap untuk menghadapi kendala-kendala dalam melakukan perubahan.

2. Kepala bagian perdagangan dalam negeri harus menjamin sumber daya manusia yang berkompetensi dan berkualitas dalam menggunakan sistem e-commerce.

\section{KESIMPULAN}

Menghasilkan analisis yang berupa proses bisnis baru, ERD, arsitektur informasi, arsitektur data, data flow diagram, arsitektur aplikasi, rancangan sistem, jaringan logistik, arsitektur teknologi, struktur organisasi, arsitektur antarmuka dan antarmuka pengguna. Pemodelan dan perancangan sistem e-commerce yang dihasilkan dapat direkomendasikan kepada Disperindagkop dan UKM DIY bidang perdagangan dalam negeri. Hal ini dibuktikan dari pengujian analisis kepada pegawai Dinas Perindagkop dengan prosentasi $100 \%$ dan pengujian prototype dengan hasil masing-masing responden pembeli nilai 3,3 pedagang IKM nilai 3,1 dan pegawai Dinas nilai 3. Hasil pengujian menjelaskan bahwa analisis dan rancangan antarmuka dapat direkomendasikan untuk pembutan pemodelan dan perancangan sistem e-commerce bidang perdagangan dalam negeri.

Daftar Pustaka

Wong, Jony. 2010. Internet Marketing For Beginners. Jakarat: PT Elex Media Komputindo.

Peraturan Gubernur Daerah Istimewa Yogyakarta Nomor 43 tahun 2008.Yogyakarta.

Renstra Dinas Perindagkop dan UKM DIY 2012-2017. 2012. Yogyakarta. 
Leveraging the Zachman framework implementation using action-research methodology - a case study: aligning the enterprise architecture and the business goals, Juan Manuel Nogueira dkk, 2013.

Luftman, J., 2003. Assessing IT/business alignment.Information Systems Management, 20 (4), 9-15.

Fansyuri, Ahmad. 2012. Aplikasi E-Commerce Penjualan Parfum Secara Online. Skripsi. Yogyakarta: Program Studi Teknik Informatika Universitas Ahmad Dahlan.

\section{UCAPAN TERIMA KASIH}

Ucapan terima kasih saya tujukan kepada Dikti yang telah mendanai penelitian ini sebagai bagian dari penelitian besar CRM (Customer Relation Management). Selain itu pihak Dinas dan IKM yang ikut membantu dalam mendapatkan data yang bisa digunakan dalam penelitian ini. 